\title{
Stage 3 Prostate Cancer Treated with a Plant-Based Diet - A Case Report
}

\author{
Stewart D Rose and Amanda J Strombom* \\ Plant-Based Diets in Medicine, USA
}

Submission: February 04, 2020; Published: February 20, 2020

"Correspondence Author: Amanda Strombom, Plant-Based Diets in Medicine, 12819 SE 38th St, \#427, Bellevue, WA 98006, USA

\begin{abstract}
Treatment of early stage prostate cancer (with a Gleason score less than seven) with a plant-based diet has been studied, and efficacy noted even after 5 years. However, this is a case of a patient with Stage 3 prostate cancer, who chose to follow a plant-based diet after his diagnosis, and is still alive today, 32 years later, despite being given a prognosis of 10\% 3-year survival. The patient is a retired physician, who was given the best available treatment since his diagnosis in 1987. He also chose to follow a largely plant-based diet after his diagnosis, recognizing its potential for treating prostate cancer. He has outlasted all other patients with a similar diagnosis, who were given the same treatment at his major city-based hospital. He attributes this to his plant-based diet. This is the first case we are aware of where a patient with stage III prostate cancer exceeded his prognosis for 32 years.
\end{abstract}

Keywords: Case report, plant-based diet, prostate cancer, stage 3, vegetarian, vegan

\section{Introduction}

Treatment of early stage prostate cancer (with a Gleason score less than seven) with a plant-based diet has been studied, and efficacy noted even after 5 years [1]. However, this is a case of a patient with Stage 3 prostate cancer, who chose to follow a plantbased diet after his diagnosis, and is still alive today, 32 years later, despite being given only a $10 \%$ chance of 3 year survival. While this case is anecdotal, and a plant-based diet was combined with standard treatment, it joins a growing body of evidence that prostate cancer is responsive to treatment with a plant-based diet. The patient's longevity may also partially be the result of a plant-based diet preventing and treating common comorbidities such coronary artery disease [2], Type 2 diabetes [3], and renal failure [4].

\section{Case Report}

The patient is a 91-year old male retired physician who specialized in Internal Medicine. In 1987, at the age of 59 he was diagnosed with Stage 3 prostate cancer that had metastasized to the lymph nodes in the pelvic region. The attending physician suggested that he quit his medical practice because the prognosis only gave him a $10 \%$ chance of 3 -year survival. At the time of diagnosis, he had no other comorbidities and his weight was normal.

As a child, aged 8, he had had rheumatic fever. His doctor ordered numerous fluoroscopic exams during this time. The radiation exposure continued when, as a physician, he had a fluoroscope in his office. He found he was able to diagnose patients more quickly using this than sending the patient for an X-ray. Despite wearing a lead apron during these radiological procedures, he inevitably experienced some radiation exposure to his face and extremities. As a busy physician he had rarely had time to think about his diet, and hurriedly consumed a low fiber diet of white bread, aged cheeses and sausages, and no raw vegetables. Looking back on it now, he feels this likely contributed to his developing prostate cancer.

\section{Medical Treatment received}

The patient first underwent lymphadenectomy. The prostate and testicles were treated with radiation, which made him very weak for several weeks. Medications taken since diagnosis to treat his prostate cancer were as follows:

i. Lupron (leuprolide acetate) Taken until May 2014.

ii. Casadex - an antiandrogen. Taken until it was no longer effective.

iii. Diethylstilbestrol - discontinued due to gynecomastia and radiation treatment, and a deep vein thrombosis in his right leg.

iv. Ketoconezole - Taken until severe edema developed due to impaired renal function. His renal function improved after the ketoconazole was discontinued. 
v. Zytiga - combined with prednisone. Taken until October 2016, when it became ineffective.

vi. Xtandi - Seems to be working currently, though the dose had to be lowered due to dizziness side effects.

Over the years, the patient has switched from one medication to another as efficacy diminished and as others became available. Many of these medications gave him severe side effects. He has relied upon having his PSA monitored regularly and has tracked the effectiveness of each medication on that basis. Aspirin and other non-steroidal anti-inflammatory drugs taken for arthritis pain resulted in gastric and esophageal ulcers. He now uses the herb turmeric and cannabidiol (CBD) as anti-inflammatories.

\section{Dietary Self-treatment}

As he recovered from the initial radiation, he started to explore various alternative therapies, and was particularly drawn to the Macrobiotic diet. The patient started following the mainly vegetarian diet and has largely followed it ever since. Today he focuses on getting as much plant phytoestrogens as possible, plus the phytochemical sulforaphane, found in vegetables such as broccoli, so he consumes plenty of tofu, beans, mushrooms, and cruciferous vegetables.

However, due to the lack of good plant-based options in the retirement community where he currently lives, he finds it necessary to consume more fish and poultry than he would wish, but still avoids products from mammals - beef, pork, lamb. Recently he has had a hip replacement and both knees have been replaced. He experiences some loss of balance as a result of this, and due to sarcopenia. He has belonged to a cancer support group for the past 30 years, where other patients were being treated with similar medications, but he has outlasted them all and is now the longest-term survivor with metastatic prostate cancer in his major city-based hospital. He attributes this to his largely plantbased diet.

\section{Discussion}

This is an interesting case for several reasons. The patient is a former professor of internal medicine and so better informed than most patients. He was able to recognize the potential of a plantbased diet to treat his prostate cancer and assess its efficacy, and to consciously combine standard treatment with dietary treatment. He has outlived his prognosis for 32 years. This case also points to the problem that many senior citizens face in obtaining healthy plant-based meals in residential communities. This is all the more problematic because diet is the number one risk factor for disease and disability in the United States.

\section{References}

1. Rose S, Strombom A (2018) A plant-based diet prevents and treats prostate cancer. Canc Therapy \& Oncol Int J 11(3): 555813.

2. Rose S, Strombom A (2018) A comprehensive review of the prevention and treatment of heart disease with a plant-based diet. J Cardiol \& Cardiovas Ther 12(5): 555847.

3. Strombom A, Rose S (2017) The prevention and treatment of Type II Diabetes Mellitus with a plant-based diet. Endocrin Metab Int J Nov 5(5): 00138.

4. Rose S, Strombom A (2019) A plant-based diet prevents and treats chronic kidney disease. J0J Uro \& Nephron 6(3): 555687.

\section{Your next submission with Juniper Publishers will reach you the below assets}

- Quality Editorial service

- Swift Peer Review

- Reprints availability

- E-prints Service

- Manuscript Podcast for convenient understanding

- Global attainment for your research

- Manuscript accessibility in different formats

( Pdf, E-pub, Full Text, Audio)

- Unceasing customer service

Track the below URL for one-step submission https://juniperpublishers.com/online-submission.php 